\section{Pre-assessment triage of orthodontic referrals at an East Yorkshire Hospital}

\author{
W. J. Rayner ${ }^{1}$ and J. J. D. Neal ${ }^{2}$
}

IN BRIEF

- Raises primary dental care practitioners' awareness of the challenge of the 18 week pathway in secondary care.

- Describes a potential solution to the problem of inappropriate referrals to secondary care providers.

- Demonstrates a method of referral that places less reliance on the general dental practitioner's knowledge of IOTN.

Inappropriate referrals leading to long waiting lists are a problem for many orthodontic departments throughout the country. This paper describes a method of triaging new patient referrals which aims to reduce the number of appointments generated for inappropriate referrals. The system has been used successfully at Hull Royal Infirmary to reduce new patient waiting times in line with government targets.

\section{BACKGROUND}

Currently access to NHS orthodontic services is prioritised using the Index of Orthodontic Treatment Need (IOTN). ${ }^{1}$ NHS guidelines state that NHS treatment should normally be limited to those patients with a dental health component (DHC) of 4 or 5 and those with a DHC of 3 and an aesthetic component (AC) of 6 or more. Additionally, those patients with a DHC of less than 4 and an AC score of below 7 do not justify treatment by a hospital based consultant led team except for teaching or research purposes. ${ }^{2}$

Current Department of Health waiting time directives mean that all hospital trusts have been forced to reduce waiting times for initial outpatient consultations to 13 weeks. ${ }^{3}$ In addition by the end of 2008 no patient should have to wait more than 18 weeks from initial GP/GDP referral to the start of hospital treatment. ${ }^{4}$

Hull Teaching PCT and East Riding of Yorkshire PCT serve a population of

${ }^{1 *}$ Clinical Assistant in Orthodontics, ${ }^{2}$ Consultant Orthodontist, Department of Oral and Maxillofacial Surgery and Orthodontics, Hull Royal Infirmary, Anlaby Road, Hull, HU3 2JZ

*Correspondence to: Dr Wendy Rayner

Email:w.rayner@hotmail.co.uk

\section{Refereed Paper}

Accepted 29 February 2008

DOI: $10.1038 /$ sj.bdj.2008.348

${ }^{\bullet}$ British Dental Journal 2008; 204: 493-495 just over half a million people. Currently orthodontic services are provided by a hospital service of one consultant and one FTTA working at Hull Royal Infirmary, two specialist orthodontic practitioners working in primary care and a network of suitably trained GDPs who can provide treatment to a consultant treatment plan. The hospital service currently has the capacity to see 25 new patients for assessment every week. However, on average, the number of actual referrals exceeds this.

In order to deal with the number of referrals the hospital agreed local referral guidelines with the primary care trusts. Hull Royal Infirmary will only accept for treatment patients with an IOTN DHC of 5 (all categories), and selected patients with an IOTN DHC of 4 ; those with hypodontia (4h) and those with deep, traumatic overbites (4f), or where there is a complex medical or special needs history.

Despite these local referral guidelines, the number of patients being referred continued to exceed capacity and it has only been possible to adhere to the 13 week waiting time directive by investing in expensive out of hours waiting list initiative clinics. In order to try and dispense with these clinics a system of non-clinical pre-assessment triage using study models and radiographs has been developed for all referrals to Hull Royal Infirmary.

\section{AIMS}

The aims of the triage process are to reduce consultant new patient waiting list times and eliminate the need for waiting list initiative clinics by reducing the number of appointments generated for inappropriate referrals, and to redirect referrals, where appropriate, to the local orthodontic service providers in primary care.

\section{THE TRIAGE PROCESS}

Following consultation with the PCTs, Local Dental Committee and Managed Dental Network, all local dental practitioners were informed by letter of the new arrangements for dealing with referrals to Hull Royal Infirmary. It was emphasised that all referrals must be accompanied by a set of study models and relevant radiographs.

All referrals are examined once a week by the consultant. The study models are assessed and the IOTN DHC determined using the dental casts protocol. Referrals are then placed into one of four categories and managed accordingly as shown in Table 1.

The system makes no attempt to assess patient motivation or oral hygiene levels as this can only be done by clinical examination.

If a GDP or specialist practitioner has concerns about a patient not receiving a consultant appointment they are, of course, able to re-refer or contact 
the department directly to discuss the referral.

\section{DISCUSSION}

The triage process has now been in place for 12 months in Hull and appears to be running smoothly. New patient waiting list times have been reduced to 13 weeks and the need for waiting list initiative clinics has been eliminated.

Feedback from referring practitioners has generally been positive. One practitioner raised a concern about a perceived lack of remuneration for providing the study models required for the system under the new GDS contract.

After consulting the local adviser in dental public health, it was confirmed that the provision of study models is covered by the contract payment made to practitioners. The new GDS regulations require practitioners to provide Mandatory services. ${ }^{5}$ The provision of study models for the diagnosis, advice and planning of treatment and, where appropriate, the referral of a patient to other relevant services is included under these mandatory services.

The system is strongly reliant on good quality referrals from the primary care practitioners. The quality of the study models has been audited to ensure that they are of an acceptable standard and this will be done again at intervals to ensure this standard is maintained. As can be seen from Table 1, any unsatisfactory referrals are returned and a request made to re-refer to ensure that all referrals are of a high standard.

The number of new patient referrals allocated to each triage category was monitored over a period of 12 weeks (Table 2).

Table 2 demonstrates that over the 12 week period $31 \%$ of all new patients referred were allocated to triage categories 2, 3 or 4 and so did not receive appointments to the consultant new patient clinic. Before the triage system was introduced all of these patients would have been seen.

A criticism of this system is that perhaps patients 'slip through the net' and that amongst the patients not given hospital appointments there may be some that should, in fact, have been given one. This is an area which could be looked

Table 1 The four categories of new patient referrals and their management in the non clinical triage system

\begin{tabular}{l|l|l|} 
& Criteria & Management \\
\hline $\begin{array}{l}\text { CATEGORY 1 } \\
\begin{array}{l}\text { Consultant } \\
\text { appointment } \\
\text { required }\end{array}\end{array}$ & $\begin{array}{l}\text { Patients eligible for treatment } \\
\text { in hospital service. } \\
\text { Patients who need to be seen for } \\
\text { advice/ second opinion } \\
\text { Patients who need to be seen for treatment } \\
\text { planning where treatment is to be carried } \\
\text { out by a GDP with an orthodontic contract. }\end{array}$ & $\begin{array}{l}\text { Patient sent a consultant } \\
\text { clinic appointment. }\end{array}$ \\
\hline $\begin{array}{l}\text { CATEGORY 2 } \\
\text { No appointment } \\
\text { required }\end{array}$ & $\begin{array}{l}\text { Patients suitable for treatment by specialist } \\
\text { orthodontic practitioner. }\end{array}$ & $\begin{array}{l}\text { Referral redirected to a } \\
\text { local specialist orthodontic } \\
\text { practitioner. }\end{array}$ \\
\hline $\begin{array}{l}\text { CATEGORY 3 } \\
\text { No appointment } \\
\text { required }\end{array}$ & $\begin{array}{l}\text { Incomplete referrals. For example, inadequate } \\
\text { study models, those without study models or } \\
\text { appropriate radiographs or where more clinical } \\
\text { information is needed. }\end{array}$ & $\begin{array}{l}\text { Referral returned to the } \\
\text { GDP with an explanation } \\
\text { and a request to re-refer } \\
\text { correctly. }\end{array}$ \\
\hline $\begin{array}{l}\text { No appointment } \\
\text { required }\end{array}$ & $\begin{array}{l}\text { too early } \\
\text { not eligible for NHS treatment } \\
\text { require simple advice, such as advice } \\
\text { on simple interceptive extractions }\end{array}$ & $\begin{array}{l}\text { Letter from consultant } \\
\text { to GDP giving appropriate } \\
\text { advice. }\end{array}$ \\
\hline
\end{tabular}

Table 2 The number of new patient referrals allocated to each triage category over a 12 week period

\begin{tabular}{|l|l|l|l|l} 
& Category 1 & Category 2 & Category 3 & Category 4 \\
\hline $\begin{array}{l}\text { Total no. } \\
\text { of referrals }=318\end{array}$ & $218(69 \%)$ & $40(12.5 \%)$ & $20(6 \%)$ & $40(12.5 \%)$
\end{tabular}

into further but anecdotal evidence would suggest that, with the high standard of referrals demanded of the system and with good communication between the hospital service and local practitioners, this is not a particular problem.

The problem of inappropriate referrals leading to long waiting list times has been documented previously. ${ }^{6}$ Other methods of screening new patient orthodontic referrals have been studied. Clinician agreement for screening patients form clinical photographs has been found to be low. ${ }^{7}$ In a randomised controlled trial using teledentistry as a method of screening, the inappropriate referral rate for the teledentistry group was significantly lower than in the control group. However, GDPs had concerns over its cost effectiveness in terms of set up costs, clinical time and remuneration. ${ }^{8,9}$

As NHS regulations determine whether or not a patient is eligible for NHS treatment using the IOTN, it seems appropriate to apply this index as a way of assessing new referrals. It is also fast to use and easy to explain to both GDPs and patients. The system does not require any extra investment and very little, if any, extra clinical time from GDPs.

In order to deliver an 18 week patient pathway by the end of 2008 it is likely that local PCTs will follow government recommendations and alter the eligibility criteria for hospital treatment to the following groups:

1. Multidisciplinary cases ie orthognathic cases

2. Minor oral surgery cases ie where there are impacted or unerupted teeth

3. Severe hypodontia cases

4. Complex medical history cases

5. Special needs cases.

This will reduce the number of patients eligible for hospital treatment. In these circumstances the triage system would 
be run as it is currently but the referrals would be assessed to the new criteria.

\section{CONCLUSION}

Using this system consultant new patient waiting list times have been reduced and the need for out of hours waiting list initiative clinics eliminated. This is to the advantage of staff, patients and the local primary care trusts.

Patients with the most severe malocclusions can be identified earlier along with those requiring simple interceptive treatment. A similar system in specialist orthodontic practice would enable those patients requiring hospital care to be identified at an earlier stage.

The process has proved to be an effective referral management system which could be used as an aid in helping to deliver the18 week patient pathway.

1. Brook P, Shaw W C. The development of an index of orthodontic treatment priority. Eur J Orthod 1989; 11: 309-320.

2. Department of Health. Strategic commissioning of primary care orthodontic services. September 2006.

3. Department of Health. The NHS Plan: a plan for investment, a plan for reform. July 2000.

4. Department of Health. The NHS Improvement Plan: putting people at the heart of services. June 2004.

5. Department of Health. The National Health Service (General Dental Services) regulations 2005.

6. O'Brien K, McComb J L, Fox N, Bearn D, Wright J. Do dentists refer orthodontic patients inappropriately? Br Dent J 1996; 181: 132-136.

7. Mandall N A. Are photographic records reliable for orthodontic screening? J Orthod 2002; 29: 125-127.

8. Mandall N A, O'Brien K D, Brady J, Worthington $H V$, Harvey L. Teledentistry for screening new patient orthodontic referrals. Part 1: A randomised controlled trial. Br Dent J 2005; 199: 659-662.

9. Mandall N A, Qureshi U, Harvey L. Teledentistry for screening new patient orthodontic referrals. Part 2: GDP perception of the referral system. Br Dent J 2005; 199: 727-729. 